\title{
An eastern promise of regeneration
}

\section{The East Coast corridor of New Jersey, Delaware and Pennsylvania is poised for renewed growth in biomedicine. Claudia Caruana investigates.}

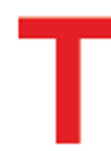

he science and engineering corridor that stretches through New Jersey, Delaware and Pennsylvania has been somewhat sleepy in recent years. A slew of corporate consolidations and staff cutbacks put the brakes on the region's economy, stifling its growth. But now this sleeping giant is beginning to stir, and job prospects are rising in both industry and academia.

The northeast corridor is home to a number of drug companies, including Merck, Pfizer, Wyeth, Johnson \& Johnson and Schering-Plough, all of which have a presence in New Jersey. Many of the region's larger drug firms are looking to expand their research and development (R\&D) operations, says Buster Houchins, vice-president of Christian \& Timbers of Columbia, Maryland, which recruits for many of the companies in the corridor.

“Today, there are many more 'smaller drugs' in the companies' pipelines, in contrast to just a few potential blockbusters," Houchins says. "These smaller drugs are coming to market soon and, although they may have fewer marketing bucks attached to them, their positioning in the market will mean more $R \& D$ personnel will be needed.

In fact, Houchins believes that the recent problems faced by both Merck and Pfizer, which centred on health scares surrounding their COX-2 inhibitor painkillers, could paradoxically generate more jobs in the region. The companies may well end up seeking new R\&D directions, he says, and this could mean a number of new positions in fresh business units. Pfizer, whose consumer healthcare division is based in Morris Plains, New Jersey, is already moving this way. Earlier this month it broke ground on the first building in a $\$ 500$-million R\&D expansion at its Morris Plains site.

\section{Poised for growth}

A general maturing of the biotech sector is also helping to fuel demand for new recruits, notes Julie Kampf, president of executive search firm JBK Associates in Englewood, New Jersey. Last year, her firm saw a $30 \%$ rise in healthcare searches, many of which Kampf attributes to biotechnology firms morphing into larger biopharmaceutical companies. "Biopharmas usually hire people with different skill sets, so new people are needed," says Kampf. "And many of these companies are growing significantly in their more traditional businesses, too. Many of the available technical positions we've filled have been in New Jersey."

But it's not just New Jersey that is seeing growth Delaware is also experiencing a rise in biomedical research and commercial opportunities. Chemical giant DuPont, based in Wilmington, broke ground for its first building in the state in 1802, and has been an important part of Delaware's economy ever since.

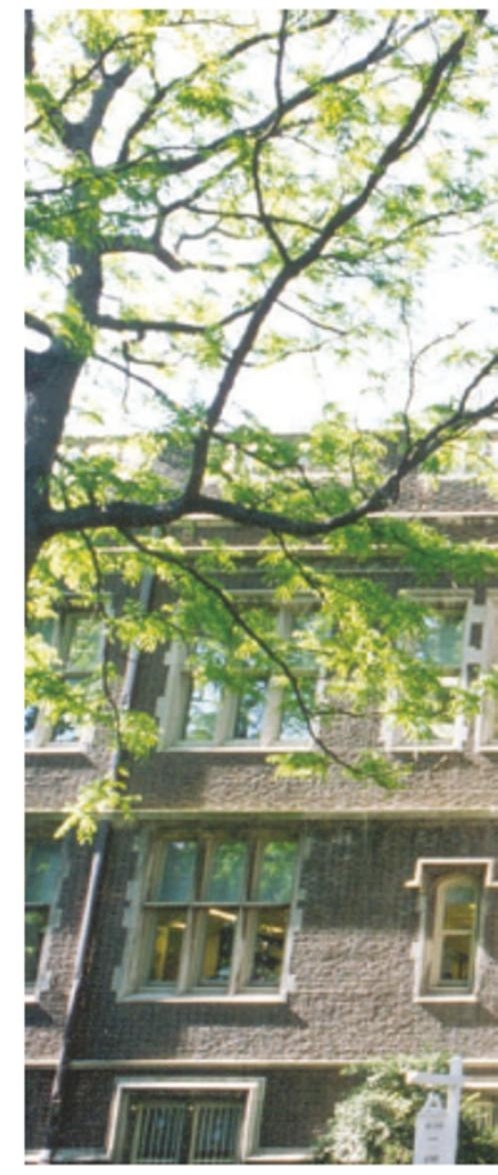

Follow the leader: Benjamin Franklin sits in the grounds of the University of Pennsylvania (above), inspiring students and postdocs alike.

\section{PITTSBURGH'S NICHE}

Pittsburgh in Pennsylvania is carving a productive niche for itself in biotechnology: regenerativemedicine.

"We have strengths here in Pittsburgh that you will not find in other major research centres," says Alan Russell, director of the McGowan Institute for Regenerative Medicine at the University of Pittsburgh. "We focus on that strength."

Regenerative medicine includes tissue engineering, cell therapy and the use of medical devices associated with these techniques.

Russell says that millions of dollars have been invested in his institute to support research and development, new construction and clinical trials. The influx of both scientists and funds has energized the community, he adds.

The University of Pittsburgh is where the Salk polio vaccine was developed. It now ranks seventh in terms of funding from the National Institutes of Health, and also receives cash from local and regional sources. It is the largest employer in the local healthcare system with 20 hospitals and research centres, and it anticipates hiring an additional 20 researchers specializing in

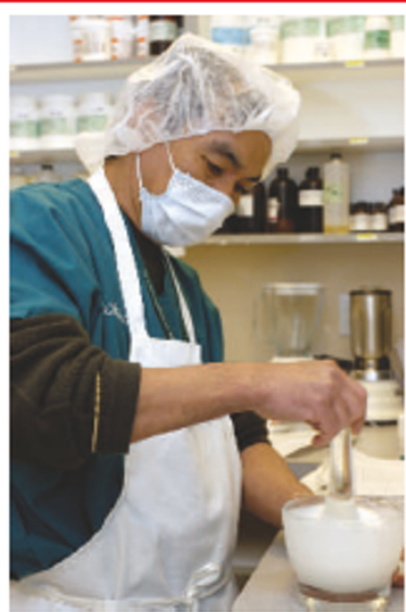

Healthcare research is a major priority for Pennsylvania. regenerative medicine over the next three years.

But the university is not alone in the area when it comes to regenerative medicine. It's neighbour, Carnegie Mellon University's Center for Bone Tissue Engineering, is collaborating with Pittsburgh in an attempt to use muscle stem cells to regenerate bone. Jeffrey Hollinger, director of the centre, says that he is planning to hire lab technicians and a cell biologist soon. Although hardly a recruitment stampede, this may signal an upward trend for this burgeoning field. 

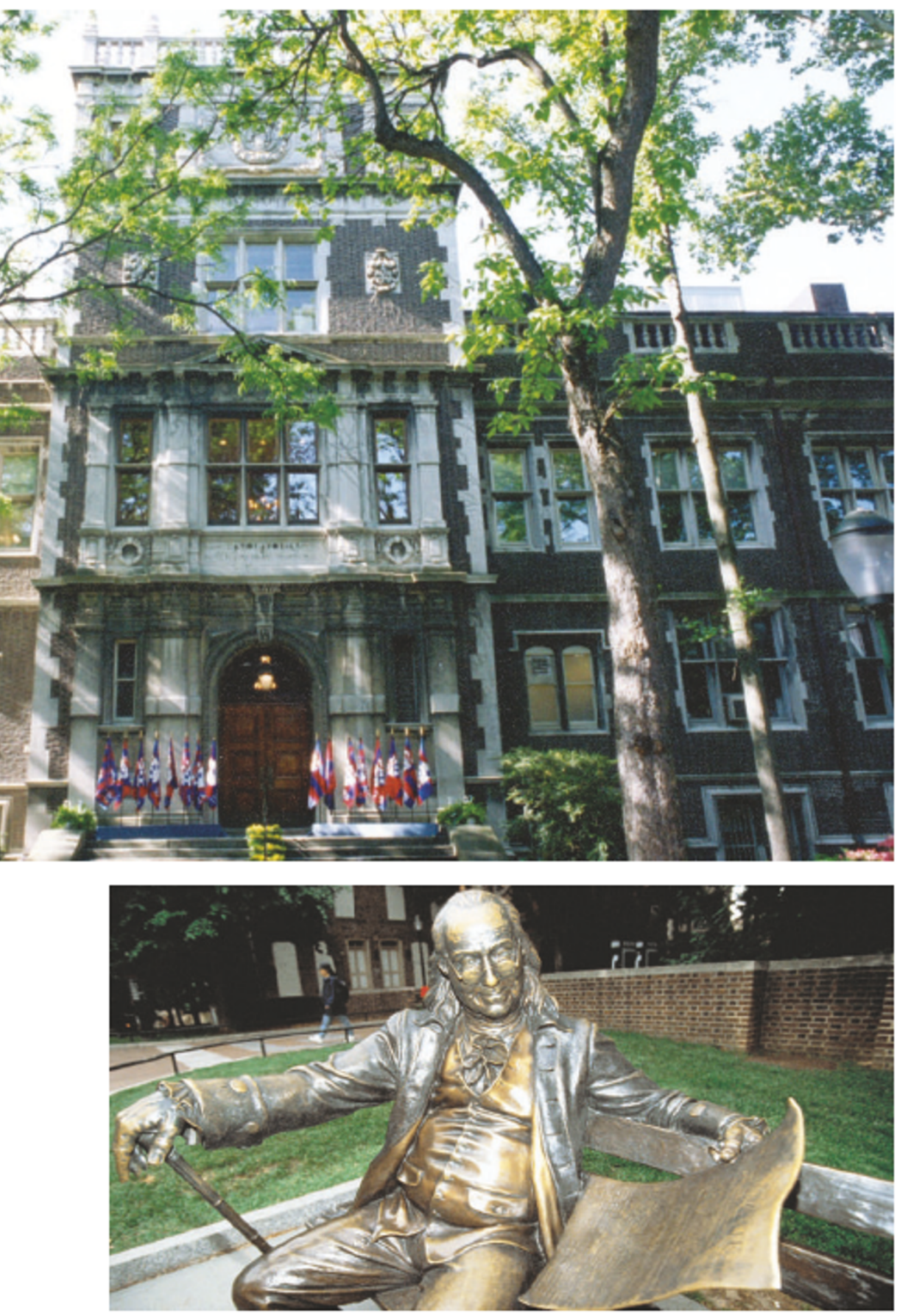

Although it has no real biopharmaceutical business, it often hires people with skill sets suitable for such operations. "We continue to be interested in the use of advanced materials sciences for medical uses, and hire materials scientists and biomedical engineers at all levels," says John Pierce, the company's director of biosciences and engineering.

DuPont actively recruits from universities around the world. One tool it uses is its Young Professors grant programme, which is designed to provide unrestricted start-up assistance to promising young and untenured research faculty members. To date, more than $\mathbf{5 0 0}$ new scientists have received funding through this programme. ${ }^{\alpha}$ We are looking for talented, experienced scientists from across the market spectrum, including industry, academia and government," says Pierce.

Farther north, in Pennsylvania, Philadelphia is undergoing something of a renaissance. Although it

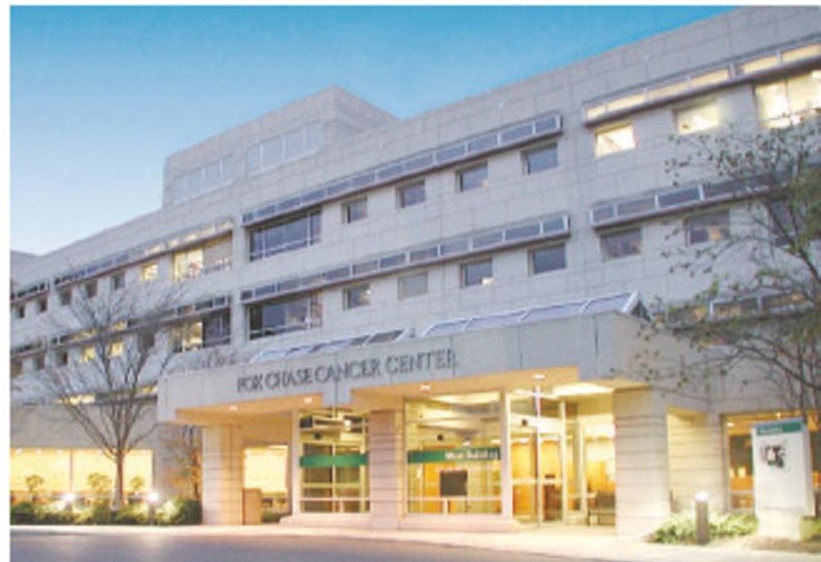

The Fox Chase Cancer Center expects to generate 4,000 new jobs over the next 20 years.

isn't the only biomedical centre in the state (see 'Pittsburgh's niche', opposite), Philadelphia is seeing a number of medical and research powerhouses expand their presence in the city. The Fox Chase Cancer Center, for instance, is spending $\$ 1$-billion over the next 20 years, which by the end will bring in some 4,000 new jobs, many of which will require advanced technical degrees. Similarly, the Wistar Institute, a biomedical research centre on the University of Pennsylvania's campus, is also expanding.

The Wistar was responsible for the world's most widely used rubella vaccine and led work on recombinant-DNA vaccines with a rabies vaccine for animals in the 1980 s. Today it is continuing its leading role in the field by collaborating with global pharmaceutical companies. For instance, a rotovirus vaccine developed at the institute is currently undergoing phase III clinical trials through a collaboration with Merck.

Five years ago, there were 26 labs at the institute; now there are 34. Current plans mean that its needs to have an additional eight labs by the end of this decade, says Franklin Hoke, spokesman for the institute.

The Wistar is focusing its growth on four key areas: systems biology (genomics, bioinformatics and proteomics), vaccine development, stem-cell biology and chemical biology (particularly the design of small molecules for drug development). It expects to hire new researchers and postdocs to maintain growth in these areas.

\section{Need for postdocs}

At the University of Pennsylvania itself, the number of postdoc positions is steady. But campus recruiting is strong, says a university spokesperson, with postdocs finding themselves in demand with industry as well as academia.

Joyce Gioia, president of management consultants the Herman Group in Greensboro, North Carolina, says that biotechnology and pharmatechnology jobs are growing by leaps and bounds in the northeast corridor. ${ }^{\circ}$ The particular scientific degree people have doesn't seem to matter, she says. There is a critical shortage of qualified technical people in the corridor, she adds, particularly in biotechnology. "We don't see a downturn in hiring for the foreseeable future," she adds.

Claudia Caruana is a freelance writer based on Long Island, New York. 